\title{
A Research on Reducing the Weight of Semi-Trailer Frame Manufactured in Vietnam
}

\author{
Truong Dang Viet Thang*, Nguyen Trong Hoan, Trinh Minh Hoang \\ Hanoi University of Science and Technology, Hanoi, Vietnam \\ *Email: thang.truongdangviet@hust.edu.vn
}

\begin{abstract}
This article analyses and proposes suitable approaches to improve frame structures in term of weight reduction for heavy-duty truck chassis frame in general and semi-trailer frame in particular. Specifically, this study focused on reducing the weight of frame side members, which makes up the primary mass of the vehicle chassis. Some variants of design to evaluate its efficiency and applicability on semi-trailer frame were proposed. The study explored maximum stress and deformation within the frame structure under static loading conditions using the integrated finite element analysis and multi-body simulation based on which some modified designs from the existing frame was proposed to reduce the weight of the chassis frames, including altering the main beam's material property, cross-section dimension, or lightening holes. The analysis results were presented in plots of the stress and deflection spectrum of the frame in numerical simulations. The proposed approaches were analysed and discussed to find out the appropriate improvement method for the heavy truck frame and the semi-trailer frame suitable for the truck manufacturers in Vietnam.
\end{abstract}

Keywords: chassis frame, semi-trailer, optimisation, lightweight, CAE.

\section{Introduction}

The semi-trailer frame is the major component supporting and keeping the entire cargo in the container stable under all operating conditions. The vehicle frame is designed to ensure strength and robustness to withstand vibrations, vertical impacts, torsional and bending vibrations while travelling. The latest trend of chassis technology for heavy-duty trucks has been led to higher load capacity and lower weight while ensuring vehicle strength and durability. Despite some certain limitations, the current domestic manufacturing technology-based semi-trailer in Vietnam still has significant durability and safety in most operational conditions. Compared with the domestic product, the imported semi-trailer has many advantages such as compact structure, unibody structure, lightweight, larger allowable payload, and longer lifetime. For example, the two axles $40 \mathrm{ft}$ semi-trailer of CICM, one of the top semi-trailer manufacturers, has a tare weight of $3,800 \mathrm{~kg}$ and a payload of $40,000 \mathrm{~kg}$. This semi-trailer proves the capability of carrying a large payload on a lightweight skeleton frame.

In order to promote research and development activities for domestically manufactured semi-trailer generally, it is required to deploy computer-aided engineering (CAE) tools to analyse and evaluate durability and fatigue life so that the optimised frame structure and the proper material selection could be

ISSN 2734-9373

https://doi.org/10.51316/jst.150.ssad.2021.31.1.11

Received: 12 January 2021; accepted: 17 May 2021 achieved from the beginning phase of the design process. Nowadays, CAE applications are more and more widely used in the design and optimisation of the chassis before actual production and testing taking place. For semi-trailer chassis frame, the optimal strategy is often focused on reducing its weight while ensuring durability in the following options:

- $\quad$ Altering frame side members' material property.

- $\quad$ Lightening holes to reduce unnecessary masses without affecting the strength of the chassis frame.

- Modifying section properties of the frame side rail by changing the thickness provided that keeping its section modulus remained.

So far, very few research on improving the semi-trailer frame has been carried out as they are often designed and manufactured with reference to the existing patterns. Not much attention has been paid to this issue, especially in Vietnam. Most studies on the optimisation methods of the heavy-duty truck frame structure in general and the method for evaluating the durability of the chassis were published after structural changes. Some works demonstrated that using advanced high strength steels (AHSS), as well as high-strength low-alloy steels (HSLA), would be a key solution for weight reduction and strength enhancement of vehicle chassis frame structure [1] or other three different materials were deployed for the truck chassis frame as grey cast iron, alloy steel AISI4130 and ASTM A710 [2]. In term of lightening holes, [3] determined 
the location to create the holes in the integrated frame to reduce the weight of the chassis frame during the design cycle while remaining the frame strength and $[4,5]$ found that the multi holes model is the best design chassis providing the highest of torsional stiffness and the lowest mass [6 - 8] and [9] focused on weight reduction of chassis by varying thickness and height of the flange. [9, 10] showed how topology and tonometry optimisations were more convenient for an early development stage, whose outcome could be further refined through size and shape optimisations.

\section{Simulation Modeling}

Firstly, the existing semi-trailer frame was modelled from the $40 \mathrm{ft}, 2$-axle flatbed carrying container semi-trailer domestically produced with its technical parameters and frame material shown in Table 1 . Then, the 3D model was meshed by using Hypermesh/Hyperworks. More details of the method and the technique of generating the model were found in [11] by the same authors and in [12].

Table 1. Dimension and weight of the semi-trailer

\begin{tabular}{lll} 
Specification & Parameter & Unit \\
\hline Overall length & 12,500 & $\mathrm{~mm}$ \\
Overall width & 2,480 & $\mathrm{~mm}$ \\
Payload & 27,200 & $\mathrm{~kg}$ \\
Frame Rail (HxBxL) & $500 \times 140 \times 11986$ & $\mathrm{~mm}$ \\
Material & $\mathrm{Q} 345$ & - \\
\hline
\end{tabular}

Meshing is a crucial step in pre-processing phase of the finite element analysis (FEA). In order to achieve the precision and accuracy of the meshing model, the meshing process should be based on the structural configuration of the existing frame and the meshing criteria for evaluating mesh element quality in the Hypermesh environment. In this study, the chassis is modelled based on the combination of 2D and $1 \mathrm{D}$ elements with properly structural assumptions to reduce computational time while ensuring the accuracy of the model. In addition, some details are described by the 1D elements such as cross member, subframe and welds.

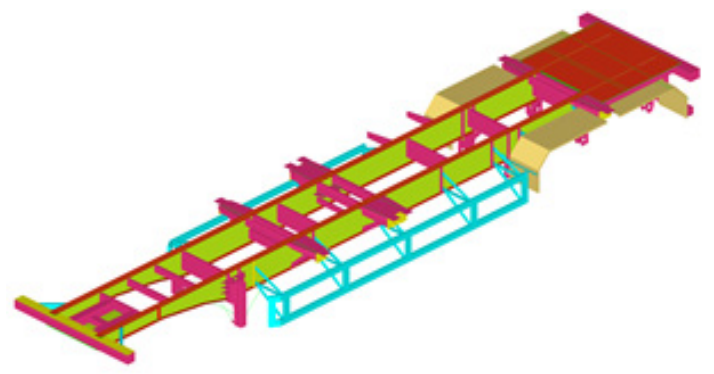

Fig. 1. Meshing model of semi-trailer frame.

Welds are described with a specialised 1D element to describe weld characteristics in the model best. The meshing model of the entire frame is shown in Fig. 1. The multi-body system of combination tractor and semi-trailer was built in the module Motionview/Hyperworks. This MBS model was composed of bodies like a tractor, container, kingpin, fifth-wheel, tractor's front/rear suspension systems, and semi-trailer's the rear tandem axle with their constraints (joints, ordinaries, springs and dampers).

The structural compositions of the suspension system are simulated in the multi-body system (MBS) model to describe the system characteristics with the aim to reflect the overall behaviour of the vehicle in the actual operation conditions. The tractor and semitrailer combination is linked with a road by suspensions and wheels. In this work, it was assumed that leaf spring was considered as a single coil spring and placed to the centre point of the spring.

The front/rear suspension system for the tractor and tandem axle trailer suspension of the semi-trailer is shown in Fig. 2 and Fig. 3.

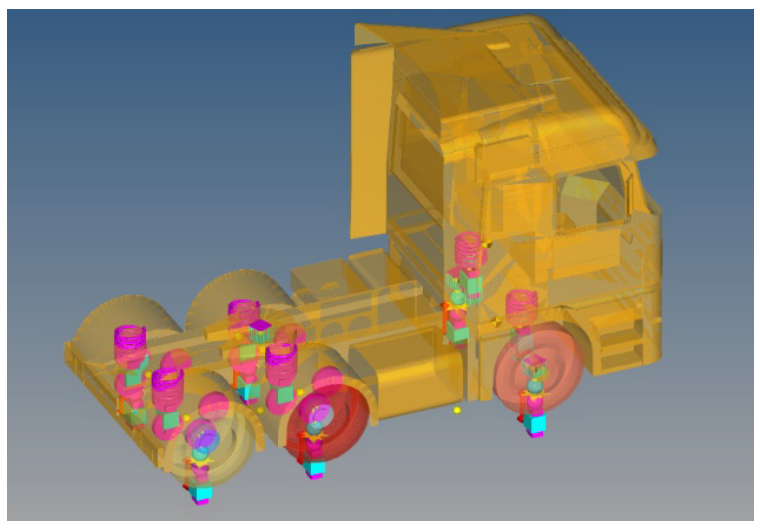

Fig. 2. Tractor with front/rear suspensions

The kingpin of the semi-trailer frame is aligned on the fifth-wheel on the tractor. The rear of the frame is elastically coupled to the wheel via rear suspension and wheel. Wheel-to-ground contact was described by using a specific contact in MotionView. The force outputs acting on the frame at joints between frame members and suspension components, including the maximum allowable payload of the container, from the flexible model as shown in Fig. 3 will be imported into the finite element model of the frame as constraints and boundary conditions to evaluate the durability in the next step.

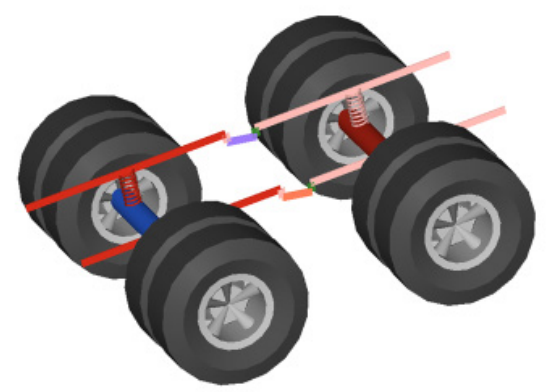

Fig. 3. Rear tandem axle trailer suspension 
The entire vehicle MBD model utilised in this paper consists of multi-body dynamic model of tractor- semi-trailer combination and the flexible frame of the semi-trailer as illustrated in Fig. 4.

The virtual simulation process has two phases: Finite element (FE) analysis and multi-body dynamics simulation (MBD). Structures considered in the FE model is the whole frame structure of a semitrailer made in Vietnam.

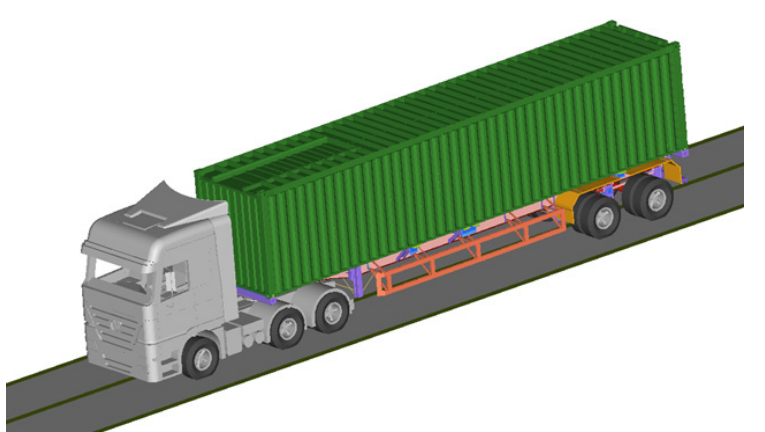

Fig. 4. The entire vehicle model

For each proposed variant to modify or reform the geometry of the existing frame. Simulation events were defined and added to closely physical tests performed in the static condition described in detail in a subsequent section. As shown in Fig. 5, the load extraction was achieved from a multi-body dynamics (MBD) full-vehicle model to solve the flexible frame's stress and deformation response through plots and animations.

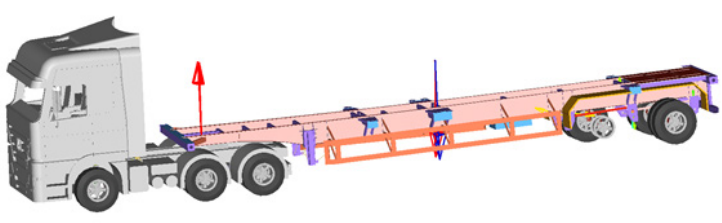

Fig. 5. Loadings and force outputs applied on semitrailer frame

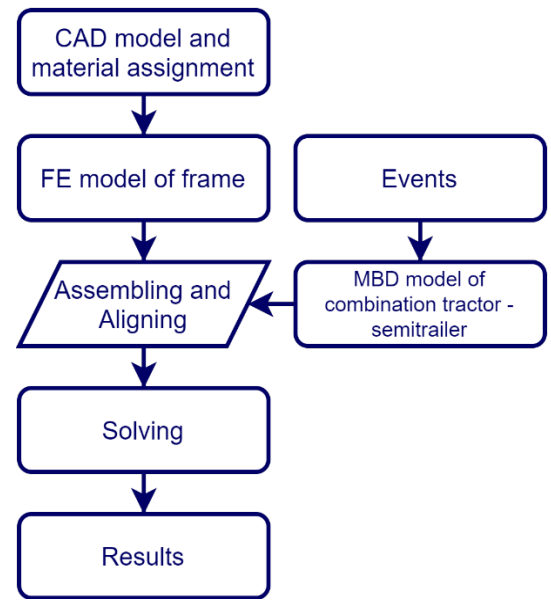

Fig. 6. Flow chart for integration methodology
The workflow of the proposed integration methodology is shown in Fig. 6.

\section{Proposed Case Studies and Loading Conditions}

\subsection{Frame Materials}

For trucks, chassis frame can be made from medium hardness, low alloy steel. Advanced highstrength steel and alloy are more widely used to make chassis, especially for making the two main beams of the frame. In the finite element (FE) model employed for this study, the material properties of frame rails were changed to explore weight reduction using high strength steel shown in Table 2, where Q345 steel was the original.

Table 2. Material properties used in FE model.

\begin{tabular}{lllll}
\hline Case & Material & $\begin{array}{l}\text { Modulus of } \\
\text { elasticity } \\
(\mathrm{MPa})\end{array}$ & $\begin{array}{l}\text { Density } \\
(\mathrm{kg} / \mathrm{m} 3)\end{array}$ & $\begin{array}{l}\text { Yield } \\
\text { Strength } \\
(\mathrm{MPa})\end{array}$ \\
\hline 1 & Q345 & 206,103 & 7850 & 345 \\
2 & $\begin{array}{l}\text { ATSM } \\
\text { A710 }\end{array}$ & 205,103 & 7798 & 515 \\
3 & $\begin{array}{l}\text { ATSM } \\
\text { A514 }\end{array}$ & 200,103 & 7800 & 690 \\
\hline
\end{tabular}

\subsection{Frame Side Rail Cross-Section}

The side rail of the semi-trailer's ladder frame structure is often made from H-shaped, Channelshaped or Box-shaped beam. In reality, the frame chassis structure of heavy-duty truck manufactured and assembled in Vietnam has the main beams in the $\mathrm{H}$-shaped, which are laterally connected by cross members made of U-shaped beam. Reforming the side rail members of the frame chassis with the $\mathrm{H}$ section beam was considered to reduce the weight frame while keeping the chassis frame geometry properties and load capacity unchanged. As proposed in [7], this work attempted to modify the dimension of beam height $H$ and the flange thickness $t_{2}$ as shown in Fig. 7 in a reversed modification.

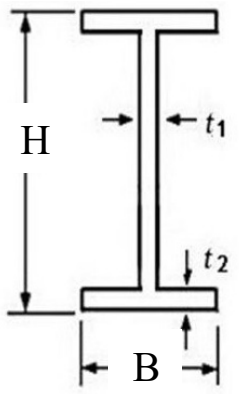

Fig. 7. H-section beam

For $H$ beam, the section modulus related to the neutral axis is calculated as follows: 


$$
S_{x}=\frac{I_{x x}}{y}
$$

where, $y=\frac{H}{2}$

$$
S_{x}=\frac{B H^{3}-(B-t)(H-2 t)^{3}}{6 H}
$$

where $B, H, t_{1}$ and $t_{2}$ are flange width, beam height, web thickness and flange thickness.

It is assumpted that $t_{1}$ and $t_{2}$ are much smaller than $B$ and $H$, respectively. Then, the expression (2) becomes:

$$
\begin{aligned}
& S_{x}=\frac{B H^{2}-B\left(H-2 t_{2}\right)^{2}}{6 H} \\
& \frac{3 S_{x}}{2 B}=t_{2} H-t_{2}^{2}
\end{aligned}
$$

Differentiating the above expression for $H$ with respect to $t_{2}$ :

$$
-t_{2} \frac{d H}{d t_{2}}=H
$$

Using (5) to propose the following sectional dimensions as shown in Table 3.

Table 3. Proposed sectional dimensions

\begin{tabular}{llll}
\hline Case & $\mathrm{H}(\mathrm{mm})$ & $\mathrm{t}_{2}(\mathrm{~mm})$ & $\mathrm{B}(\mathrm{mm})$ \\
\hline 1 (origin) & 500 & 16 & 140 \\
4 & 531.25 & 15 & 140 \\
5 & 546.875 & 14 & 140 \\
\hline
\end{tabular}

The study result in [7] showed that reducing flange thickness could make the weight smaller but deflection and shear stress higher. Therefore, this study attempted to reduce the beam thickness and increase the beam's height $H$. However, the beam height depends not only on the overall structure layout of the vehicle but also on the actual manufacturing conditions. Therefore, the only case No. 4, detailed as in Table 3, was conducted.
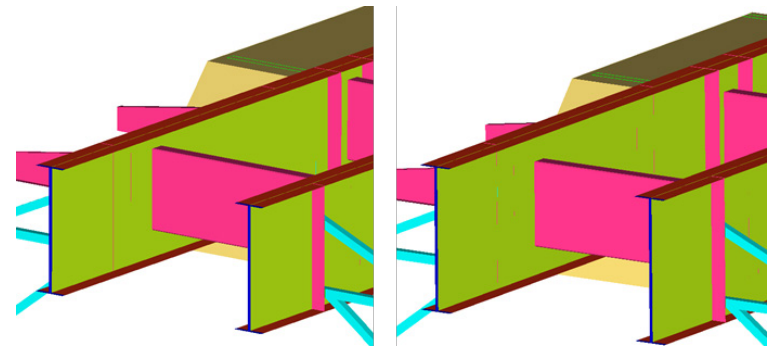

Fig. 8. The existing and modified cross-section of the side $\mathrm{H}$ beam
The thickness and height of the side $\mathrm{H}$ beam modified in the CAD model, the left one representing the existing frame, and the right one showing the proposed frame, as shown in Figure 8.

\subsection{Lightening Holes}

Lightening hole is considered as a structural part used in mechanical design to eliminate unnecessary mass, as described in [11]. The holes are usually circular or elliptical, or polygonal in shape, founded in [4]. The position and size of the hole depending on the structure, joints with other parts, components and accessories determined by the FEA, which defines a safe area to propose a cutting plan. In the truck frame structure, these holes help reduce the weight of the chassis frame itself and simultaneously increase the torsional stiffness of the entire structure of the chassis as described in [13]. Lightening hole location and dimension depend on the FEA results of the existing frame model, namely the first case, Case No. 1 in this study.

When the vehicle travelling on an uneven road under a specific payload, resultant forces will be generated that in turn causes the frame to bend, torsion or impact. These holes become the weakest point of the chassis structure, contributing to the rapid deterioration of the frame. According to the preliminary survey, after putting in operation, the cracks appeared in the joining area between the main beam and cross member of some semi-trailer frames that were first manufactured in Vietnam. Then the frame structure was improved by cutting holes with the size and the location just as a reference frame without considering how to determine the low-stress area to propose the hole-cutting plan.

Table 4. Proposed study cases

\begin{tabular}{lll}
\hline No. & Case Study & Details \\
\hline 1 & $\begin{array}{l}\text { Frame siderail } \\
\text { Q345B (original } \\
\text { case) }\end{array}$ & $\begin{array}{l}\text { Material properties } \\
\text { founded in Table 2 }\end{array}$ \\
2 & $\begin{array}{l}\text { Frame side rail } \\
\text { ATSM A710 }\end{array}$ & $\begin{array}{l}\text { Material properties } \\
\text { founded in Table 2 }\end{array}$ \\
3 & $\begin{array}{l}\text { Frame side rail } \\
\text { ASTM A514 }\end{array}$ & $\begin{array}{l}\text { Material properties } \\
\text { founded in Table 2 }\end{array}$ \\
4 & $\begin{array}{l}\text { Main cross member } \\
\text { 2 lightening holes }\end{array}$ & $\begin{array}{l}8 \text { holes at 4 major } \\
\text { cross members }\end{array}$ \\
5 & $\begin{array}{l}\text { Main cross member } \\
\text { 3 lightening holes }\end{array}$ & $\begin{array}{l}\text { 12 holes at 4 major } \\
\text { cross members }\end{array}$ \\
6 & $\begin{array}{l}\text { Various thickness } \\
\text { H-section beam }\end{array}$ & $\begin{array}{l}\mathrm{H}=531.25 \text { mm } \\
\mathrm{t}=15 \mathrm{~mm} \text { B }=140 \mathrm{~mm}\end{array}$ \\
\hline
\end{tabular}




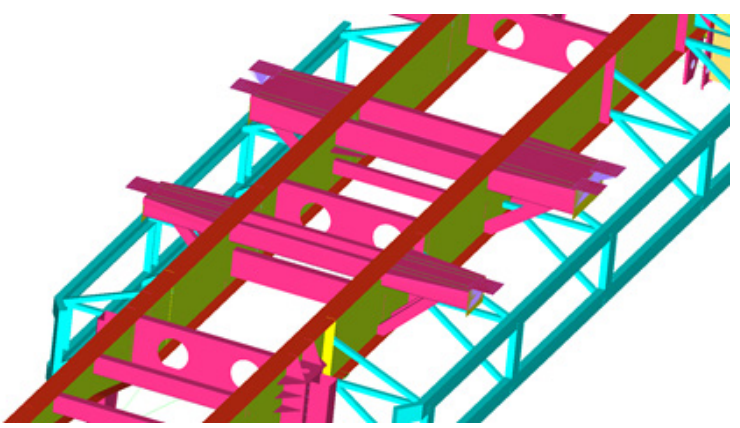

Fig. 9. Two lightening holes at cross members

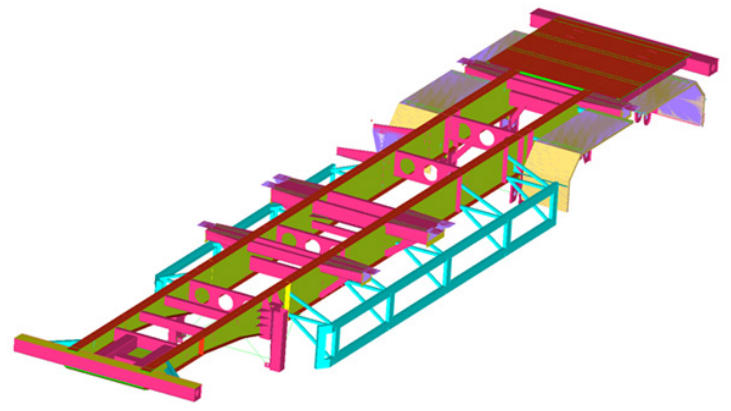

Fig. 10. Two lightening holes at cross members

Lightening holes should be implemented in the non-critical areas added to the vehicle's frame to reduce the frame weight while maintaining its good durability based on analysis results with the help of CAE tools. However, if there are too many holes, the problem may come causing negative impacts on durability, lifetime and, perhaps, even safety and ride comfort.

There are two options proposed in this study. The first option is to drill two holes at the four primary cross members of the existing semi-trailer frame. The second option is to cut three holes at the four cross members, as in the first option. The modifications of the geometry of the existing chassis were shown in Fig. 9 and Fig. 10 for the first option and second option, respectively.

\subsection{Case Studies}

Proposed case studies in this paper were modelled, simulated and assessed through finite element analysis to explore maximum stress and deformation of the frame at critical positions in typical static loading conditions.

In summary, there were six proposed models for analysis, where case 1 is the original frame. The case studies from No. 2 to No. 6 are the five proposed frame modifications detailed in Table 4.

\section{Key findings and Discussions}

\subsection{Static Loading Conditions}

The virtual tests in this work were conducted to evaluate the durability of semi-trailer chassis frame in three typical static loading conditions as follows:

Test 1: Full payload on a flat road.

Test 2: Full payload, all rear wheels on $20 \mathrm{~cm}$ height bumper.

Test 3: Full payload, all rear wheels of the right side on $20 \mathrm{~cm}$ height bumper.

These tests are designated $A, B$, and $C$, respectively, in Table 5.

\subsection{Results}

There are six case studies in which the first one is the original design and the rest are five modified frames listed in Table 5. The graphical results plotted are stress, deformation or displacement distribution that was solved and analysed under the three load conditions listed in Section 4.1.

Regarding the optimisation problem, it is beneficial to locate the high-stress and largedeformation areas of the chassis frame because these analysed results are significant to know structural behaviour inside the frame to propose improved variants. In the line of this work, the simulated results of the equivalent stress distribution (von Mises) and the vertical deformation of the semi-trailer frame are used to analyse and discuss.

For the first case study, the original frame design, the results show that maximum stress and largest deformation in the simulations occurred in the frame structure is in the range of the allowable yield strength of the chassis material, namely the maximum stress values are $104 \mathrm{Mpa}, 603.8 \mathrm{Mpa}, 469 \mathrm{MPa}$, respectively as shown from Fig. 11 to Fig. 13. These values are acceptable as compared to the maximum allowable stress values of frame material. These results also correspond to the actual design of most semi-trailers in Vietnam, often being designed and manufactured more durable than required.

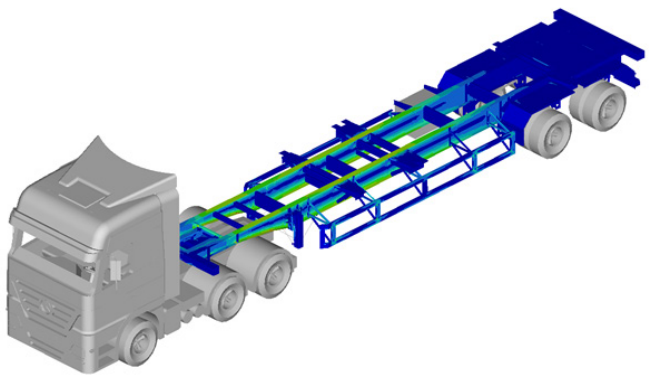

Fig. 11. Stress distribution of the existing frame in test A 


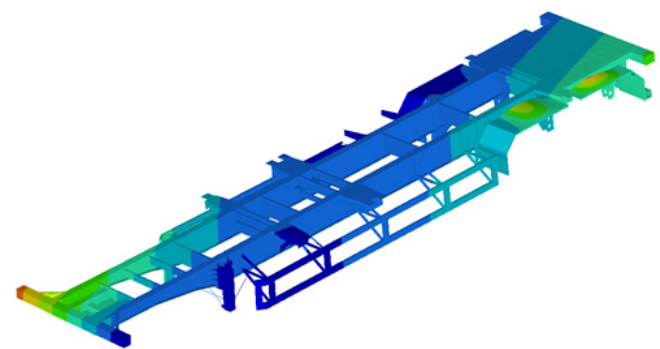

Fig. 12. Deformation of the existing frame in test B

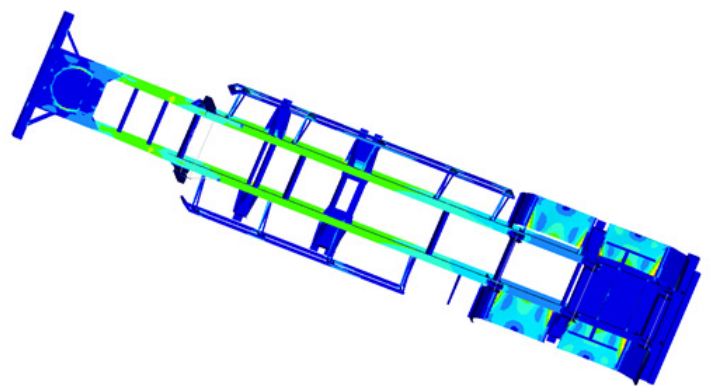

Fig 13. Stress distribution of the existing frame in test C

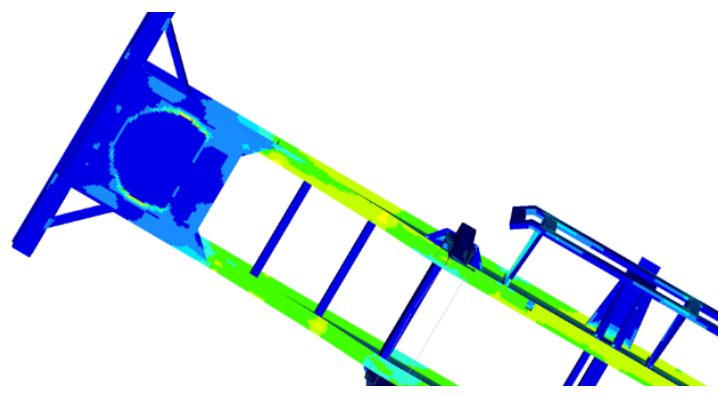

Fig. 14. Stress distribution of case study 4 in test A

These above plots of stress and deformation distribution along the length of the two main $H$ beams show that the high-stress and large-deformation areas were located in the middle part of the frame under bending conditions in tests $A$ and $B$, as shown in Fig. 14 and Fig. 15; concentrated in the upper and the lower parts of the frame, especially the areas around the placement mounting the frame members together as shown in Fig. 16 under the torsional condition of test $C$.

These high-stress and large-deformation areas distributed along with the length of the main two $\mathrm{H}$ beams, the frame side rails, are consistent with theory and practices. Indeed, many heavy-duty trucks and specialised vehicles are often reinforced at these areas for improvement design or after a certain period of time in use.

It is also clearly observed that stress distribution at cross members in these tests had the minimum magnitude of the stress range. Therefore, these initial results play an essential role to propose the propper hole cutting plan for case studies No. 4 and No. 5.

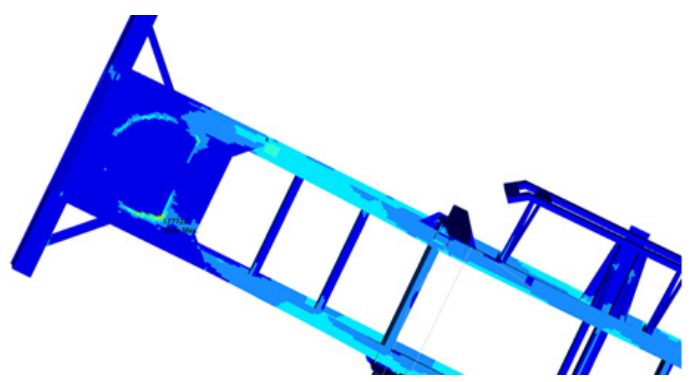

Fig. 15. Stress distribution of case study 4 in test B

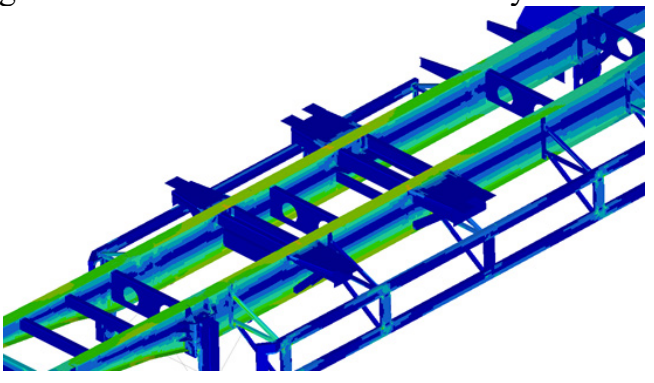

Fig. 16. Stress distribution of case study No. 4 in test C

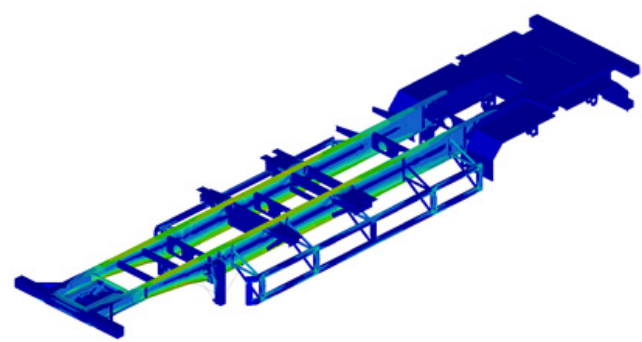

Fig. 17. Stress distribution of the frame in case study No.5

The following simulation results shown in Fig. 17 and Fig. 18 are stress and deformation responses inside the frame structure in some cases of the modified frame from case study No. 2 to No. 6 . The summary of results of proposed options in virtual tests simulated in Hyperworks platform were listed in Table 5, including the maximum magnitude of deformation and stress at critical points, the side rail mass, the entire frame mass and the weight reduction in percentage of the modified frame from the existing one.

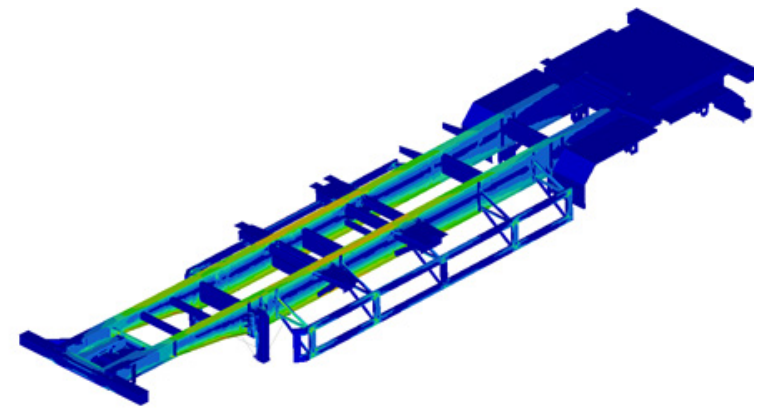

Fig. 18. Stress distribution of the frame in case study No.8 
JST: Smart Systems and Devices

Volume 31, Issue 1, May 2021, 084-091

Table 5. The summary of results of proposed options in virtual tests

\begin{tabular}{|c|c|c|c|c|c|c|c|}
\hline No. & Case & & $\begin{array}{l}\text { Deformation } \\
(\mathrm{mm})\end{array}$ & $\begin{array}{l}\text { Max. Stress } \\
(\mathrm{MPa})\end{array}$ & $\begin{array}{l}\text { Frame Mass } \\
(\mathrm{kg})\end{array}$ & $\begin{array}{l}\text { Frame Rail } \\
\text { Mass (kg) }\end{array}$ & $\begin{array}{c}\text { Weight } \\
\text { Reduction (\%) }\end{array}$ \\
\hline \multirow{3}{*}{1} & \multirow{3}{*}{ Steel Q345B } & $\mathrm{A}$ & 25.9 & 174 & \multirow{3}{*}{3,280} & \multirow{3}{*}{2,000} & \multirow{3}{*}{-} \\
\hline & & $\mathrm{B}$ & 118.6 & 603.8 & & & \\
\hline & & $\mathrm{C}$ & 155 & 469 & & & \\
\hline \multirow{3}{*}{2} & \multirow{3}{*}{ Steel ATSM A710 } & $\mathrm{A}$ & 26.2 & 174 & \multirow{3}{*}{3,266} & \multirow{3}{*}{1,986} & \multirow{3}{*}{0.7} \\
\hline & & $\mathrm{B}$ & 105 & 600 & & & \\
\hline & & $\mathrm{C}$ & 45.2 & 320 & & & \\
\hline \multirow{3}{*}{3} & \multirow{3}{*}{ Steel ASTM A514 } & $\mathrm{A}$ & 26.8 & 174 & \multirow{3}{*}{3,265} & \multirow{3}{*}{1,987} & \multirow{3}{*}{0.65} \\
\hline & & $\mathrm{B}$ & 70.1 & 598 & & & \\
\hline & & $\mathrm{C}$ & 46.3 & 321.7 & & & \\
\hline \multirow{3}{*}{4} & \multirow{3}{*}{ Two lightening holes } & $\mathrm{A}$ & 25.9 & 174,7 & \multirow{3}{*}{3,245} & \multirow{3}{*}{1,965} & \multirow{3}{*}{1.75} \\
\hline & & $\mathrm{B}$ & 104.4 & 615.8 & & & \\
\hline & & $\mathrm{C}$ & 46.5 & 324 & & & \\
\hline \multirow{3}{*}{5} & \multirow{3}{*}{ Three lightening holes } & $\mathrm{A}$ & 25.8 & 174.7 & \multirow{3}{*}{3,227} & \multirow{3}{*}{1,947} & \multirow{3}{*}{2.65} \\
\hline & & $\mathrm{B}$ & 103 & 605.5 & & & \\
\hline & & $\mathrm{C}$ & 47.7 & 315 & & & \\
\hline \multirow{3}{*}{6} & \multirow{3}{*}{ Thickness $\mathrm{H}$ beam } & A & 22.3 & 150 & \multirow{3}{*}{3,270} & \multirow{3}{*}{2,000} & \multirow{3}{*}{$\sim 0$} \\
\hline & & $\mathrm{B}$ & 97.5 & 657.5 & & & \\
\hline & & $\mathrm{C}$ & 39.4 & 274 & & & \\
\hline
\end{tabular}

The summary of results for all variants proposed was presented briefly in Table 5 .

From the summary of analytical results, the optimal options No. 2 and No. 3 using high-strength steel ASTM A710 and low-carbon alloy steel ASTM A514 for the frame, respectively, show that the global bending and torsional stiffness of the frame structure increase, which produce lower deformation while the equivalent stress is primarily similar to case No. 1, the existing frame chassis. Therefore, these two proposals could contribute to reducing frame weight and its increased durability.

In proposed cases No. 4 and No. 5, the lightening holes at the major cross members were cut, the maximum stress and deformation occurred in the chassis are lower than the original prototype frame under the same loading conditions, which proves that the lightening holes could help both, reducing weight and increasing the load-supporting capacity of the chassis frame. That would prevent vehicle frame structure from dynamic load impact during the operation and improve the fatigue life of the vehicle. Thus, the optimal proposes of the lightening hole make the semi-trailer frame weight lighter the most $(2,65 \%)$.

\section{Conclusion}

This study deals with several feasible approaches that could be deployed to the process of designing and manufacturing frames for heavy-duty trucks and semi-trailer manufactured in Vietnam without affecting the existing chassis frame structure and layout of the entire vehicle. The options proposed by this study would help improve the chassis frame through reducing weight of the semi-trailer chassis by several measures, namely altering the material properties, cutting holes on the crossbar members, and modifying the thickness of the main beams.

The results show that the material used originally for the existing frame made the weight of the semi-trailer chassis frame not only heavier but also weaker. In the same loading conditions, it has a larger deflection and higher stress occurred inside the frame affecting the strength of the chassis. Proposed optimisation variations for semi-trailer frame in term of lightweight of the frame is not much but shows better load-supporting capacity. The lightening hole method seems to be the most. It should be considered to optimise regarding multi-target optimal approach for a heavy-duty truck like semi-trailer at the beginning phase in the new concept design.

This study, to some extent, has made a good contribution to theoretical models such as FE and MBD in improving vehicle frame design. In practices, the analysis results are also used as a reference for Vietnam's automotive manufactures developing truck and trailer quicker and more efficient. It certainly saves significant time and effort over a traditional, manually iterative approach. However, articulated vehicles like tractor and semitrailer combination usually carry full payloads and travel on different road profiles. Therefore, to improve the heavy-duty truck frame, it is necessary to carry out some experiments to verify the finite element model and the MBD model of the entire vehicle, which utilised to evaluate its fatigue life in the next stage of this study.

\section{Acknowledgements}

This work was sponsored by the Hanoi University of Science and Technology under the project T2018-PC-039. Special acknowledgement is 
also given to the Altair Engineering ASEAN Company for exploiting Hyperworks ${ }^{\circledR}$ software in this research.

\section{References}

[1] Sohmshetty, R. and Mallela, K., Advanced high strength steels for shassis structures, SAE Technical Paper 2008-01-0854, 2008 https://doi.org/10.4271/2008-01-0854

[2] Akash Singh Patel, Atul Srivastava, 2016, Modeling, analysis \& optimization of TATA 2518 TC Truck chassis frame using CAE Tools, IJERT Volume 05, Issue 10 (October 2016). 6-7, https://doi.org/10.17577/IJERTV5IS100122

[3] Patil, Hemant B. et al. Stress analysis of automotive chassis with various thicknesses. IOSR Journal of Mechanical and Civil Engineering 6 (2013): 44-49. 45, https://doi.org/10.9790/1684-0614449

[4] Sithik, M., Vallurupalli, R., Lin, B., and Sudalaimuthu, S., Simplified approach of chassis frame optimization for durability performance, SAE Technical Paper 2014-01-0399, 2014, https://doi.org/10.4271/2014-01-0399

[5] Bhat, R., Sharma, N., Rivard, C., and Thomson, K., Simplified approach for optimising lightening holes in truck frames for durability performance, SAE Technical Paper 2017-01-1345, 2017. 7-8, https://doi.org/10.4271/2017-01-1345

[6] Yilmazcoban, I.K., \& Kahraman, Y.. Truck chassis structural thickness optimization with the help of finite element technique. The Online Journal of Science and Technology, 2011.

[7] Patel Vijaykumar V., Prof. R. I. Patel, Structural analysis of automotive chassis frame and design modification for weight reduction, IJERT ISSN: 2278-0181, Volume-1, Issue-3, May 2012, pp. 1-6 34.

[8] Ojo Kurdi, Roslan Abdul Rahman, b and Pakharudin Mohd Samin, Optimisation of heavy duty truck chassis design by considering torsional stiffness and mass of the structure, Applied Mechanics and Materials Vol 554 (2014) pp 459-463. 5-6, https://doi.org/10.4028/www.scientific.net/AMM.554 .459

[9] S Prabakaran, K. Gunasekar, Structural analysis of chassis frame and modification for weight reduction, ISSN: 2277-9655, Volume-3(5), pp. 595-600. 9-10.

[10] Marco Cavazuuti, Luca Splendid, structural optimization of automotive chassis: theory, setup, design, structural and multidisciplinary optimisation, 2011 pp. 1-3. 10-11.

[11] Truong Dang Viet Thang, Nguyen Trong Hoan, Developing a model to study the durability of a semitrailer chassis frame in Hyperworks, Proceedings of National Conference on Machines and Mechanisms, Vol. 1, pp. 494-501. Dec 8-9, 2017.

[12] Pappalardo C.M., Biondo A., Oliva A., Guida D. (2020) A general method for performing an integrated CAD-MBD-FEM analysis. In: Tonkonogyi V. et al. (eds) Advanced Manufacturing Processes. InterPartner 2019. Lecture Notes in Mechanical Engineering. Springer, Cham, https://doi.org/10.1007/978-3-030-40724-7 27

[13] Gawande, S.H., Muley, A.A. \& Yerrawar, R.N. Optimization of torsional stiffness for heavy commercial vehicle chassis frame. Automot. Innov. 1, 352-361 (2018) https://doi.org/10.1007/s42154-018-0044-6 